THE INTERNATIONAL

REVIEW OF RESEARCH IN

OPEN AND DISTANCE LEARNING

\title{
Assessment of Learner Acceptance and Satisfaction with Video-Based Instructional Materials for Teaching Practical Skills at a Distance
}

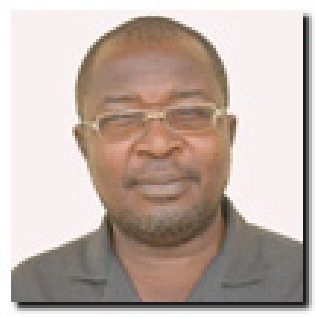

Francis Donkor

University of Education, Winneba, Ghana

\section{Abstract}

As video-based instructional materials become available to distance learners to learn practical skills at a distance, it is important to assess the instructional effectiveness of these materials and to understand how students respond to them. This paper is the second part of a larger exploratory study that assessed the instructional effectiveness of video-based instructional materials for teaching distance learners practical skills in block-laying and concreting and how learners respond to these instructional materials. Specifically, this paper aims to assess learners' acceptance and satisfaction with the materials. It also aims to determine whether levels of learner satisfaction and acceptance differ according to study centres. Data were collected from 71 respondents at three study centres using a self-completion questionnaire comprising 17 Likert-type items. The data were analyzed using descriptive statistics, ANOVA, and Scheffe's post hoc test at a 0.05 level of significance. Learners appeared positive about their learning experiences with the use of video-based instructional materials to learn practical skills at a distance as they rated highly all the items assessing their acceptance and satisfaction. Results of item-by-item ANOVA regarding learner acceptance indicated that the respondents, categorized according to study centres, exhibited similar levels of acceptance for nine of the ten items. For learner satisfaction, there were no statistically significant differences for six of the seven items. Thus, learners of different study centres exhibited about the same level of acceptance and satisfaction.

Keywords: Block-laying and concreting; distance learning; learner acceptance; learner satisfaction; technical and vocational education and training (TVET); technology acceptance model (TAM); video-based instructional materials 


\section{Introduction}

The teaching of practical skills via distance learning poses a challenge, especially for technical and vocational education and training (TVET) disciplines. Teaching practical skills, whether within a conventional educational institution or via distance learning, requires the use of precise instructions to enable learners to follow the process and thereafter repeat the skill (Hampton, 2002). Traditionally, print-based instructional materials have been used to teach practical lessons at a distance. This is buttressed by Hampton, who indicates that "for open and distance learners, the most frequently used method for teaching practical skills is print-based illustrations of step-by-step procedures" (p. 84). However, the use of printbased materials has its shortcomings, and therefore, in recent times, alternatives such as video-based instructional materials (VBIMs) have been sought (Donkor, 2010).

The use of video in the delivery of practical lessons has some advantages that are acknowledged in the literature. One such advantage, advanced by Mishra (2001), is that video is useful in showing practical and real-life activities. Mishra further argues that video can be used to capture hazardous and costly experiments for presentation and for repeated use. For the teaching of practical skills to open and distance learners, Hampton (2002) sees video as "a successful medium because it links the audio and the visual together to provide a multisensory experience for the learner” (p. 85). Hampton further observes that video makes it possible for the learner to play, replay, pause, and rewind to specific sections of the lesson, and further contends that "because practice and rehearsal is so important in developing competency, video is particularly well placed” (p. 85). Zhang, Zhou, Briggs, and Nunamaker (2006) hold the view that "video allows students to view actual objects and realistic scenes, to see sequences in motion, and to listen to narration” (p. 17). Though video resources are expensive to produce, Tooth (2000) admits that they are very useful where practical demonstrations of skills are required. From an economic perspective, Jung (2005) sees the merit of using video resources in the cost savings expected from reuse.

A literature search for the present study did not find empirical studies that investigated users' acceptance and satisfaction with video-based materials in the delivery of practical lessons at a distance. However, Wetzel, Radtke, and Stern (cited in Zhang et al., 2006) have indicated that research suggests that instructional video increases learners' interest in the subject, as well as motivation to learn. Also, it has been reported that students find video materials attractive, leading to higher degrees of satisfaction (Kearney \& Treagust, 2001; Piotrow, Khan, Lozare, \& Khan, 2000). Similarly, Zhang et al. (2006) have reported positive effects of interactive video on both learning outcomes and learner satisfaction in e-learning.

In spite of the aforementioned strengths, not much is encountered in the literature regarding empirically documented works about the use of video to teach practical skills at a distance, especially for TVET disciplines. In Ghana, the President's Special Initiative on Distance Learning is using video-based instructional materials to teach practical skills, including in the delivery of a block-laying and concreting course via distance learning. Don- 
kor (2010) has compared the instructional effectiveness of the video-based instructional materials and the traditional print-based instructional materials. He found the video-based instructional materials to be pedagogically superior to the print-based instructional materials for the teaching of practical skills at a distance. However, there has not been any empirical study to assess user acceptance and satisfaction with the video-based instructional materials. This part of the larger exploratory study focuses on learner acceptance and satisfaction with the video-based instructional materials used in teaching practical block-laying and concreting lessons.

User acceptance and satisfaction with video-based instructional materials for teaching practical skills at a distance has not received much attention in the literature. Empirical studies are therefore required to answer such questions as "how acceptable are video-based instructional materials to learners?" and "how satisfied are learners with video-based instructional materials?" As video-based instructional materials become available to distance learners to learn practical skills at a distance, it is important to assess the instructional effectiveness of these materials. It is equally important to understand how students respond to them. In view of the latter, this paper addresses itself to the following three objectives:

1. to assess students' acceptance of video-based instructional materials;

2. to assess students' satisfaction with video-based instructional materials; and

3. to determine whether levels of learner satisfaction and acceptance differ according to study centres.

\section{Instructional Materials of the President's Special Initiative on}

\section{Distance Learning}

The Ghana government established the President's Special Initiative on Distance Learning (PSI-DL) in April 2002 to coordinate and implement alternate models of education in the country (for additional information, see Donkor, 2010). In September 2007, PSI-DL started open schooling at the pre-tertiary level with the piloting of the teaching and learning by distance of two courses, Block-Laying and Concreting and Catering, using study centres in six existing TVET institutions and in five prisons in Ghana. Five of the institutions offer both courses, whilst the sixth offers only Catering.

Learners are provided with self-instructional materials to study at home on their own, and they attend tutorial sessions fortnightly at the study centres. The learning of theory is achieved through print-based instructional materials; practical skills acquisition is achieved through either print-based illustrations of step-by-step procedures or video-based practical lessons that learners access using computers or VCD players at home or at the study centres. Practical skills acquisition is consolidated through hands-on activities in workshops 
and laboratories during face-to-face sessions at the study centres under the supervision of an instructor/tutor.

For the production of the video-based practical lessons, the topics and sub-topics are first logically sequenced, written by experienced practicing teachers, and thoroughly reviewed by experts. The lessons, thus written, are converted into production scripts, shot, edited, and dubbed onto VCDs. Students of conventional TVET institutions are used for the shooting of the lessons, which are facilitated by teachers well experienced in the teaching of practical skills. The shooting, editing, and dubbing onto VCDs are carefully done by a team of experts to guarantee quality instructional materials regarding content, text, images, and sound. The result is that the final material, when viewed, has clearly visible images, comprehensible and easy-to-read text with bold, clear fonts, good contrast with the background, and a clean, uncluttered screen.

\section{The Theoretical Framework for Assessing Learner Acceptance}

\section{of Video-Based Instructional Materials}

On the basis of Dillon's (2001) definition of "user acceptance" in relation to information technology, learner acceptance is defined for the purposes of this study as the demonstrable willingness within a user of instructional video technology (VCD type) to employ it to learn practical skills. The conceptual foundation of the learner acceptance aspect of the present study was based on the technology acceptance model (TAM). According to Turner, Kitchenham, Brereton, Charters, and Budgen (2010), TAM was proposed by Fred Davis in 1989 as a means of predicting technology usage. TAM postulates that perceived ease of use and perceived usefulness of technology are predictors of user attitude toward using the technology, subsequent behavioural intentions, and actual usage (Davis, 1993; Masrom, 2007). The TAM employed for this study is shown in Figure 1.

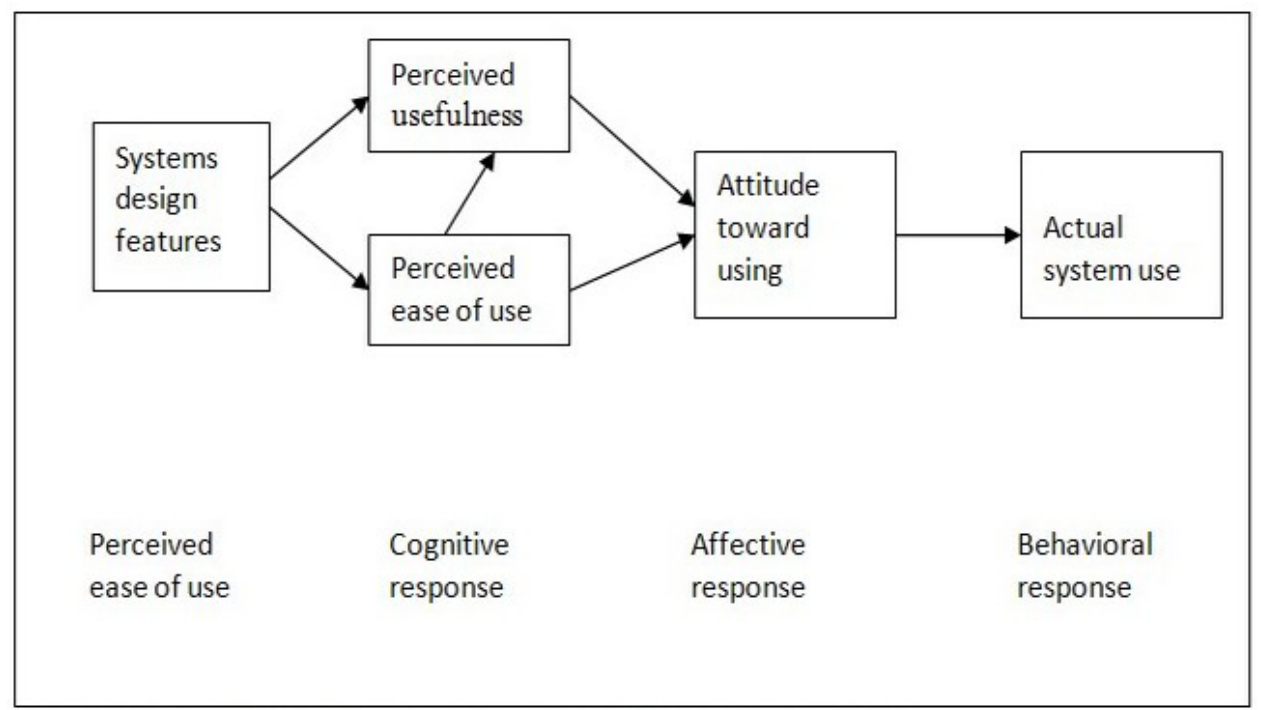

Figure 1. Original Technology Acceptance Model (Davis, 1993, p. 476). 
Masrom (2007) describes perceived usefulness as the degree to which the user believes that using the technology will improve his or her work performance, while perceived ease of use "refers to how effortless he or she perceives using the technology will be" (p. 3). According to Masrom, both perceived usefulness and perceived ease of use are considered distinct factors influencing the user's attitude toward using the technology, though perceived ease of use is also hypothesized to influence perceived usefulness and attitude toward using the technology. Finally, such attitude toward using the technology determines the behavioural intention to use that technology.

\section{Methodology}

\section{Research Design}

The study employed a cross-sectional descriptive survey with a researcher-designed questionnaire for data collection. Since the study sought to assess the instructional materials of an ongoing programme, the survey research method was deemed appropriate. In the view of Osuala (1993), the survey method is appropriate for conducting studies into ongoing processes. The survey design is also the most preferred in situations where the data to be collected are about self-reported beliefs or behaviours (Neuman, 2000). The choice of the survey method was also informed by the views of Johnson and Christensen (2008), who have indicated that such data can be collected in a relatively short period of time.

\section{Population and Sample}

The population comprised all 151 learners who registered during the 2007/2008 academic year at the five study centres (institutions) to study Block-Laying and Concreting via distance learning (note that the sixth institution offers only Catering). They were all males. Anecdotal evidence suggests that this is consistent with male dominance in Block-Laying and Concreting in the formal, classroom-based school system. The study sample, as also reported in Donkor (2010), consisted of all of the 73 learners at three study centres purposely drawn from three zonal divisions in Ghana, namely Ramseyer Technical Vocational Institute and Technical Institute, Kumasi for the Middle Zone $(n=15)$, Bolgatanga Technical Institute for the Northern Zone ( $n=25)$, and Takoradi Technical Institute for the Southern Zone $(n=33)$.

In addition to the assessment of learner acceptance and satisfaction, the larger study of which this paper is part also assessed the instructional effectiveness of the video-based instructional materials for teaching practical lessons (see Donkor, 2010). The latter aspect of the study involved a performance test to assess the practical skills acquired by students. To have involved the entire population $(N=151)$ in the performance test would have been extremely expensive, impractical, and time-consuming, and would have also required the services of many research assistants. The larger study also aimed to assess the instructional effectiveness of the video-based instuctional materials on one hand and the acceptance of and satisfaction with the materials on the other hand. Thus, the researcher decided to use students $(n=73)$ from three of the five study centres that were involved in the first part of 
the larger study.

\section{Instruments}

A self-completion questionnaire was used for the study. Questionnaires are easy to administer, user-friendly, and fast to score. Therefore, it takes relatively little time for the respondents and researchers to complete and score the questionnaires. Additionally, similar user-acceptance studies have used researcher-designed self-completion questionnaires for data collection (King \& He, 2006; Legris, Ingham, \& Collerette, 2003; Schepers \& Wetzels, 2007; Turner et al., 2010).

A 17-item questionnaire relating to learner acceptance (Learner Acceptance Scale) of and satisfaction (Learner Satisfaction Scale) with video-based instructional materials was used for the study. The respondents were required to indicate their agreement or disagreement with the questionnaire items on a four-point Likert-type scale. If the traditional five-point scale is used, respondents have the tendency to select responses in the centre of the scale (Anderson, 1985; Casley \& Kumar, 1988; Downie, 1967). The responses for the four-point scale were: strongly agree (4), agree (3), disagree (2), and strongly disagree (1).

Ten items based on the technology acceptance model (TAM) were used to assess learner acceptance of the video-based instructional materials. As indicated above, TAM serves as a means of predicting technology usage. A review of literature covering studies of TAM revealed that 10 items based on TAM are commonly used in "user acceptance" studies where the specific names of the technologies are used to replace "the technology" in specific questionnaires (King \& He, 2006; Legris et al., 2003; Schepers \& Wetzels, 2007; Turner et al., 2010). These 10 commonly used items were modified for the current study to make them relevant and fit the specific context of the video-based instructional materials. Among the 10 items, four each related to "perceived usefulness" and "perceived ease of use," while one item each covered "behavioural intention to use" and "actual usage." The 10 items of the Learner Acceptance Scale used for the present study and the corresponding sub-scales appear in Table 1.

To measure learner satisfaction with the video-based instructional materials, seven items were used. They covered overall (global) satisfaction, effectiveness of the materials, degree of enjoyment using the materials, and learner resolve to recommend the materials to peers. Apart from the overall (global) satisfaction item, all the items were adapted from those used by the Canarie Learning Program (2004) in evaluating the Virtual Veterinary Medicine Learning Community e-learning modules introduced into the training of Doctor of Veterinary Medicine students across Canada. The seven items of the Learner Satisfaction Scale used for this study appear in Table 3 .

In December, 2009, the researcher conducted a pilot study meant to ensure the validity and reliability of the questionnaire and to identify items that should be revised. The pilot study involved the administration of the questionnaire to a sample of 20 randomly selected learners from one of the study centres that constituted the population but was not selected for the study. The pilot study sample size of 20 was based on the observation of Borg and 
Gall (1983) that for a pilot study, it is rarely necessary to include more than 20 subjects. Participants of the pilot study were asked to complete the instrument and to provide comments or suggestions for revising any ambiguous items. The final instrument for the study was produced after analysis of the pilot data and subsequent revisions in the wording of a few items.

Cronbach's alpha reliability test for the Learner Satisfaction Scale yielded a value of o.88. For the Learner Acceptance Scale, Cronbach's alpha reliability test for the sub-scales yielded the following values: Perceived Usefulness - 0.89; Perceived Ease of Use - 0.92; Behavioural Intention to Use - 0.85; and Actual Usage - 0.88. Against the background of the observation by Johnson and Christensen (2008, p. 149) that "a popular rule of thumb is that the size of coefficient alpha should generally be, at a minimum, greater or equal to .70 for research purposes," these values of reliability indicate good internal consistency and instrument reliability. The high alpha values for the scales are consistent with previous findings and are as expected since "these scales have been validated and high reliability reported for each" (Fusilier \& Durlabhji, 2005, p. 237). The high reliability values also confirm the earlier observation of Davis (1995), the architect of TAM, that the instrument has been used extensively and has been empirically validated by several researchers investigating issues in the area of user acceptance and that "the reliability (Cronbach alpha) in most cases has been in excess of 0.9...” (p. 730).

\section{Data Collection Procedures}

The data were collected in January 2010, over three days, with a day at each of the three selected study centres. At each centre, the researcher personally administered the questionnaires to the respondents who were attending scheduled face-to-face sessions. As and when the questionnaires were completed and handed in, they were scrutinised to ensure that the respondents had properly completed them. A total of 71 out of the 73 selected distance learners took part in the study, representing an overall response rate of $97.3 \%$. This included a 100\% response rate from Ramseyer Technical Vocational Institute $(n=15)$ and Bolgatanga Technical Institute $(n=25)$. For Takoradi Technical Institute, 31 of the 33 registered learners participated in the study, representing a $93.9 \%$ response rate for the study centre.

\section{Method of Data Analysis}

The raw data were analysed using the Statistical Package for the Social Sciences (SPSS). First, descriptive statistics such as percentages, means, and standard deviations were used to analyse the data collected. The computed mean rating for each item was compared with the theoretical mean rating (assuming normal distribution of responses) of 2.50 to determine whether respondents agreed with the statements. Any computed mean of an item exceeding 2.50 indicated expression of agreement with the statement, whilst means below 2.50 indicated expression of disagreement with the statement.

An item-by-item analysis of variance (ANOVA) at a 0.05 level of significance was run to determine whether there were any statistically significant differences in the ratings of re- 
spondents categorized according to study centres. Where significant differences were established, Scheffe's post hoc test was used to make pairwise comparisons of the means to determine differences in the ratings. ANOVA assumes that the data are normally distributed and that there is homogeneity of variances. Kinnear and Gray (1992) strongly advise for the prior verification of the homogeneity assumption and further suggest the use of nonparametric tests when there is marked heterogeneity of variances. Owing to the disparity in the sample sizes of the three sub-groups, the ANOVA was preceded by a test of homogeneity of variances to verify the homogeneity assumption.

\section{Results and Discussion}

The research findings are presented in four sections according to the objectives that guided the study. The sections are as follows:

1. learner acceptance of video-based instructional materials;

2. comparison of learners' ratings of acceptance of video-based instructional materials according to study centres;

3. learner satisfaction with video-based instructional materials; and

4. comparison of learners' ratings of satisfaction with video-based instructional materials according to study centres.

\section{Learner Acceptance of Video-Based Instructional Materials}

The mean rating for each of the 10 learner acceptance items as rated by the respondents and the resultant mean rating for all the items were computed and compared with the theoretical mean rating (assuming normal distribution of responses) of 2.50. This was to determine whether students responded positively to the video-based instructional materials (VBIMs). The computed means and the corresponding standard deviations appear in Table 1.

The results that appear in Table 1 indicate that all the items had mean ratings that far exceeded the theoretical mean of 2.50. Also, the resultant mean of $3.425(S D=0.546)$ for all the items substantially exceeded the theoretical mean. As indicated in Table 1, the item "I find the VBIMs useful in acquiring practical skills in Block-Laying and Concreting" (Item \#4) had the least mean rating of $3.310(S D=0.523)$. Though it had the least mean rating, the value of 3.310 substantially exceeded the theoretical mean of 2.50. The highest mean rating of $3.592(S D=0.495)$ related to the item "I find the VBIMs easy to use" (Item \#8). The reported high ease of use could be due to the quality of the materials regarding content, text, images, and sound. Indeed, when viewed, the images appear good and visible; the texts are clearly visible and easy to read, as the fonts are bold and clear; there is good contrast with the background; and screens appear clean and uncluttered.

Thus, the results of the study showed that distant learners responded positively to the vid- 
eo-based instructional materials and that the materials were well received. It is hoped that the expressed high levels of perceived usefulness, ease of use, intention to use, and actual usage of the video-based instructional materials in learning practical skills will greatly enhance learners' motivation, interest, and practical skills acquisition.

Table 1

Descriptive Statistics of Learners' Ratings of Acceptance of Video-Based Instructional Materials

\begin{tabular}{|c|c|c|}
\hline $\begin{array}{l}\text { Element of acceptance of the video-based instructional materials } \\
\text { (VBIMs) }\end{array}$ & $\begin{array}{l}\text { Mean rat- } \\
\quad \text { ing }\end{array}$ & $\begin{array}{l}\text { Standard } \\
\text { deviation }\end{array}$ \\
\hline \multicolumn{3}{|l|}{ Perceived usefulness } \\
\hline $\begin{array}{l}\text { VBIMs improve my performance in doing practical work in Block-Lay- } \\
\text { ing and Concreting. }\end{array}$ & 3.394 & 0.597 \\
\hline $\begin{array}{l}\text { VBIMs improve my acquisition of practical skills in Block-Laying and } \\
\text { Concreting. }\end{array}$ & 3.465 & 0.530 \\
\hline $\begin{array}{l}\text { VBIMs enhance my effectiveness in performing practical work in Block- } \\
\text { Laying and Concreting. }\end{array}$ & 3.366 & 0.638 \\
\hline $\begin{array}{l}\text { I find the VBIMs useful in acquiring practical skills in Block-Laying and } \\
\text { Concreting. }\end{array}$ & $3 \cdot 310$ & 0.523 \\
\hline \multicolumn{3}{|l|}{ Perceived ease of use } \\
\hline Operating the VBIMs is easy for me. & $3 \cdot 380$ & 0.517 \\
\hline $\begin{array}{l}\text { I find it easy to get the VBIMs to learn practical lessons in Block-Laying } \\
\text { and Concreting. }\end{array}$ & 3.437 & 0.554 \\
\hline $\begin{array}{l}\text { It was easy for me to become skillful in Block-Laying and Concreting } \\
\text { with the use of the VBIMs. }\end{array}$ & 3.507 & 0.504 \\
\hline I find the VBIMs easy to use. & 3.592 & 0.495 \\
\hline \multicolumn{3}{|l|}{ Behavioural intention to use } \\
\hline $\begin{array}{l}\text { I intend to use the VBIMs regularly in learning practical lessons in } \\
\text { Block-Laying and Concreting. }\end{array}$ & $3 \cdot 35^{2}$ & 0.537 \\
\hline \multicolumn{3}{|l|}{ Actual usage } \\
\hline $\begin{array}{l}\text { I use the VBIMs regularly to learn practical lessons in Block-Laying and } \\
\text { Concreting. }\end{array}$ & 3.451 & 0.529 \\
\hline $\begin{array}{l}\text { Resultant mean for all elements of acceptance of the video-based in- } \\
\text { structional materials }\end{array}$ & 3.425 & 0.546 \\
\hline
\end{tabular}




\section{Comparison of Learners' Ratings of Acceptance of Video-Based Instructional Materials According to Study Centres}

The mean rating for each of the 10 learner acceptance items as rated by the respondents was computed for each of the three study centres that participated in the study (Table 2). The mean ratings for the three sub-groups are high and appear quite close for many of the items. This notwithstanding, it was deemed appropriate to determine whether the observed differences were statistically significant, using one-way analysis of variance (ANOVA) at the 0.05 level of significance. Due to the apparent disparity in the sample sizes of the three sub-groups ( $n=15, n=25, n=31$ ), the ANOVA was preceded by a test of homogeneity of variances. The results indicated that all the items met the requirements that the three subgroups were from a homogeneous population.

The results of the item-by-item ANOVA are reported as F-values and p-values in Table 2 (last two columns respectively). With regard to nine of the items, there were no statistically significant differences in respondents' ratings of learner acceptance for the three study centres ( $p$-value $>0.05)$. This indicates that the three sub-groups exhibited about the same levels of agreement with nine of the statements that sought to measure respondents' acceptance of the video-based instructional materials. From the ratings of the respondents regarding the nine items, there was a high degree of uniformity in the level of learners' acceptance of the use of the video-based instructional materials to teach them practical skills in block-laying and concreting. Thus, learners at the three study centres were unanimous in rating highly their acceptance of the video-based instructional materials. 
Table 2

Results of ANOVA for Ratings of Items of the Learner Acceptance Scale Categorized according to Study Centres

\begin{tabular}{|c|c|c|c|c|c|c|c|c|}
\hline \multirow[t]{2}{*}{$\begin{array}{l}\text { Elements of acceptance of video- } \\
\text { based instructional materials } \\
\text { (VBIMs) }\end{array}$} & \multicolumn{2}{|c|}{$\begin{array}{l}\text { Ratings of learners of } \\
\text { Middle Zone }\end{array}$} & \multicolumn{2}{|c|}{$\begin{array}{l}\text { Ratings of learners of } \\
\text { Northern Zone }\end{array}$} & \multicolumn{2}{|c|}{$\begin{array}{l}\text { Ratings of learn- } \\
\text { ers of Southern } \\
\text { Zone }\end{array}$} & \multirow[t]{2}{*}{$\begin{array}{c}F \\
\text {-value }\end{array}$} & \multirow[t]{2}{*}{ p-value } \\
\hline & Mean & $S D$ & Mean & $S D$ & Mean & $S D$ & & \\
\hline $\begin{array}{l}\text { VBIMs improve my performance } \\
\text { in doing practical work in Block- } \\
\text { Laying and Concreting. }\end{array}$ & $3 \cdot 333$ & 0.488 & 3.280 & 0.614 & $3 \cdot 516$ & 0.625 & 1.1880 & 0.311 \\
\hline $\begin{array}{l}\text { VBIMs improve my acquisition of } \\
\text { practical skills in Block-Laying and } \\
\text { Concreting. }\end{array}$ & $3 \cdot 533$ & 0.516 & $3 \cdot 320$ & 0.476 & 3.548 & 0.568 & 1.463 & 0.239 \\
\hline $\begin{array}{l}\text { VBIMs enhance my effectiveness } \\
\text { in performing practical work in } \\
\text { Block-Laying and Concreting. }\end{array}$ & 3.400 & 0.632 & 3.200 & 0.646 & 3.484 & 0.626 & 1.414 & 0.250 \\
\hline $\begin{array}{l}\text { I find the VBIMs useful in acquir- } \\
\text { ing practical skills in Block-Laying } \\
\text { and Concreting. }\end{array}$ & 3.267 & 0.458 & 3.240 & 0.523 & 3.387 & 0.558 & 0.604 & 0.549 \\
\hline $\begin{array}{l}\text { Operating the VBIMs is easy for } \\
\text { me. }\end{array}$ & $3 \cdot 333$ & 0.488 & $3 \cdot 320$ & 0.476 & 3.452 & 0.568 & 0.519 & 0.597 \\
\hline $\begin{array}{l}\text { I find it easy to get the VBIMs to } \\
\text { learn practical lessons in Block- } \\
\text { Laying and Concreting. }\end{array}$ & 3.267 & 0.594 & 3.240 & 0.523 & 3.677 & 0.475 & $5 \cdot 951^{*}$ & 0.004 \\
\hline $\begin{array}{l}\text { It was easy for me to become skill- } \\
\text { ful in Block-Laying and Concreting } \\
\text { with the use of the VBIMs. }\end{array}$ & 3.533 & 0.516 & 3.400 & 0.500 & $3 \cdot 581$ & 0.502 & 0.914 & 0.406 \\
\hline I find the VBIMs easy to use. & 3.600 & 0.507 & $3 \cdot 52$ & 0.510 & 3.645 & 0.486 & 0.438 & 0.647 \\
\hline $\begin{array}{l}\text { I intend to use the VBIMs regular- } \\
\text { ly in learning practical lessons in } \\
\text { Block-Laying and Concreting. }\end{array}$ & 3.333 & 0.723 & 3.280 & 0.458 & 3.419 & 0.502 & 0.470 & 0.627 \\
\hline $\begin{array}{l}\text { I use the VBIMs regularly to learn } \\
\text { practical lessons in Block-Laying } \\
\text { and Concreting. }\end{array}$ & 3.400 & 0.507 & 3.440 & 0.507 & 3.484 & 0.570 & 0.132 & 0.877 \\
\hline
\end{tabular}

*Statistically significant at .05 level, $d f=2$ for numerator and 68 for denominator (computed $\mathrm{F}$ value $>F_{\text {o.05 }(2,68)}=3.132$ ); p-value $=0.004<0.0$ 
The respondents, however, differed significantly in their rating of the item "I find it easy to get the VBIMs to learn practical lessons in Block-Laying and Concreting" ( $F=5.951$, which exceeds $F(2,68)=3.132$ required for significance at the 0.05 level; $p$-value $=0.004)$. Thus, the study centre appeared to be a determinant of the accessibility of the video-based instructional materials. To determine which study centres significantly differed, Scheffe's post hoc test (at 0.05 level of significance) was used to make pairwise comparisons of the mean ratings of the three sub-groups. The results indicated that the ratings of learners from the Southern Zone (represented by Takoradi Technical Institute) were significantly higher than the ratings of respondents from both the Middle and Northern Zones (represented by Ramseyer Technical Vocational Institute and Bolgatanga Technical Institute respectively). Thus, learners from the Southern Zone appeared to have easier access to the video lessons than their counterparts from the Middle and Northern Zones. Indeed, it has been observed that some students from the Southern Zone have access to VCD players and computers at home. Additionally, some of them have duplicated the video lessons. For these reasons, students of the Southern Zone appear to have easier access to the lessons than their counterparts from the other two zones, who can mostly access the lessons only at the study centres. A scheme needs to be put in place to give the learners of the Middle and Northern Zones equally easy access to the materials.

\section{Learner Satisfaction with Video-Based Instructional Materials}

The mean rating for each of the seven learner satisfaction items as rated by the respondents and the resultant mean rating for all the items were computed. These were then compared with the theoretical mean rating (assuming normal distribution of responses) of 2.50 to determine whether students were satisfied with the video-based instructional materials (VBIMs). The results that appear in Table 3 indicate that all the items had mean ratings that far exceeded the theoretical mean. Also, the resultant mean of $3.465(S D=0.538)$ for all the items substantially exceeded the theoretical mean of 2.50. Thus, students rated highly the learner satisfaction items. As indicated in Table 3, the item "I am satisfied with my learning from the VBIMs" (Item \#7) had the highest mean rating of $3.577(S D=0.525)$. The lowest mean rating of $3.352(S D=0.563)$ related to the item "The video lessons make me spend more time studying to acquire practical skills" (Item \#6). The results of the study showed that students are highly satisfied with the video-based instructional materials. 
Table 3

Descriptive Statistics of Learners' Rating of Satisfaction with Video-Based Instructional Materials

\begin{tabular}{|l|c|c|}
\hline $\begin{array}{l}\text { Element of satisfaction with the video-based instructional materials } \\
\text { (VBIMs) }\end{array}$ & $\begin{array}{c}\text { Mean } \\
\text { rating }\end{array}$ & $\begin{array}{c}\text { Standard } \\
\text { deviation }\end{array}$ \\
\hline I find the video lessons enjoyable. & 3.507 & 0.504 \\
\hline $\begin{array}{l}\text { The VBIMs have contributed greatly to my acquisition of relevant skills in } \\
\text { Block-Laying and Concreting. }\end{array}$ & 3.479 & 0.557 \\
\hline I find the video lessons to be effective in meeting the learning objectives. & 3.549 & 0.529 \\
\hline I would describe the video lessons as being highly interesting. & 3.423 & 0.525 \\
\hline I would recommend use of the video lessons to my colleagues. & 3.366 & 0.541 \\
\hline $\begin{array}{l}\text { The video lessons make me spend more time studying to acquire practical } \\
\text { skills. }\end{array}$ & 3.352 & 0.563 \\
\hline I am satisfied with my learning from the VBIMs. & 3.577 & 0.525 \\
\hline $\begin{array}{l}\text { Resultant mean for all elements of satisfaction with the video-based in- } \\
\text { structional materials }\end{array}$ & 3.465 & 0.538 \\
\hline
\end{tabular}

Overall (global) satisfaction with the use of the VBIMs for learning practical skills was equally very high $(\bar{x}=3.577, S D=0.525)$. This suggests that learners were overwhelmingly positive about their satisfaction levels with the VBIMs. The high overall satisfaction is an expression of high motivation for the use of the VBIMs as the learners found them enjoyable, interesting, and would recommend them to their colleagues for use. The students also found the materials to be relevant and effective. It is encouraging to see that the learners in the present study found the video lessons enjoyable as "an enjoyable learning scenario is a necessity to effective instruction" (Ghee \& Heng, 2008, p. 686). It is equally encouraging that the learners found the materials to be relevant and effective. This is because relevant and effective materials enable students to acquire specific skills, knowledge, and attitudes (Dick \& Reiser, 1989, as cited in Ghee \& Heng, 2008). Learners' expression of high satisfaction with the VBIMs should also be a source of satisfaction to the President's Special Initiative on Distance Learning, which runs the Block-Laying and Concreting programme via distance learning.

\section{Comparison of Learners' Ratings of Satisfaction with Video- Based Instructional Materials According to Study Centres}

The mean rating for each of the seven learner satisfaction items as rated by the respondents was computed for each of the three study centres that participated in the study (Table 4). The mean ratings for the three sub-groups were substantially higher than the theoretical mean of 2.50 and appeared quite close for all the items. However, it was deemed appropriate to determine whether the differences in the means were statistically significant using one-way analysis of variance (ANOVA) at the 0.05 level of significance. Due to the apparent 
disparity in the sample sizes of the three sub-groups $(n=15, n=25, n=31)$, the ANOVA was preceded by a test of homogeneity of variances. The results indicated that all the items met the requirements that the three sub-groups were from a homogeneous population.

The results of the item-by-item ANOVA are reported as F-values and p-values in Table 4 (last two columns respectively). The results show that there was uniform agreement in the responses for six out of the seven items that measured learner satisfaction as there were no statistically significant differences in the ratings of the respondents categorized according to study centres. The ratings of the respondents regarding the six items showed a high degree of similarity in the level of satisfaction with the use of the video-based instructional materials for practical skills acquisition in block-laying and concreting. Thus, learners at the three study centres were unanimous in rating highly their satisfaction with the videobased instructional materials.

The respondents, however, differed significantly in their rating of the item "The video lessons have contributed greatly to my acquisition of relevant skills in Block-Laying and Concreting" ( $F=4.727$, which exceeds $F(2,68)=3.132$ required for significance at the 0.05 level). To determine which study centres significantly differed, Scheffe's post hoc test (at 0.05 level of significance) was used to make pairwise comparisons of the mean ratings of the three sub-groups. The results indicated that the ratings of learners from the Southern Zone (represented by Takoradi Technical Institute) were significantly higher than the ratings of respondents from the Northern Zone (represented by Bolgatanga Technical Institute). A contributory factor could perhaps be accessibility to the materials. As depicted in the findings earlier reported, learners from the Southern Zone appeared to have easier access to the materials compared to learners from the other zones. With the increased access to the video-based instructional materials, the learners from the Southern Zone were likely to rate higher the contribution of the materials toward their acquisition of relevant skills in block-laying and concreting than those from the Northern Zone. 
Table 4

Results of ANOVA for Ratings of Items of the Learner Satisfaction Scale Categorized according to Study Centres

\begin{tabular}{|c|c|c|c|c|c|c|c|c|}
\hline \multirow[t]{2}{*}{$\begin{array}{l}\text { Elements of satisfaction } \\
\text { with video-based instruc- } \\
\text { tional materials }\end{array}$} & \multicolumn{2}{|c|}{$\begin{array}{l}\text { Ratings of learners of } \\
\text { Middle Zone } \\
(n=15)\end{array}$} & \multicolumn{2}{|c|}{$\begin{array}{l}\text { Ratings of learners of } \\
\text { Northern Zone } \\
(n=25)\end{array}$} & \multicolumn{2}{|c|}{$\begin{array}{c}\text { Ratings of } \\
\text { learners of } \\
\text { Southern Zone } \\
\quad(n=31)\end{array}$} & \multirow[t]{2}{*}{ F-value } & \multirow[t]{2}{*}{ p-value } \\
\hline & Mean & $S D$ & Mean & $S D$ & Mean & $S D$ & & \\
\hline $\begin{array}{l}\text { I consider the video les- } \\
\text { sons to be enjoyable. }\end{array}$ & 3.533 & 0.516 & 3.400 & 0.500 & 3.581 & 0.502 & 0.914 & 0.406 \\
\hline $\begin{array}{l}\text { The video lessons have } \\
\text { contributed greatly to my } \\
\text { acquisition of relevant } \\
\text { skills in Block-Laying and } \\
\text { Concreting. }\end{array}$ & 3.467 & 0.516 & 3.240 & 0.597 & 3.677 & 0.475 & $4.727^{*}$ & 0.012 \\
\hline $\begin{array}{l}\text { I consider the video les- } \\
\text { sons to be effective in } \\
\text { meeting the learning ob- } \\
\text { jectives. }\end{array}$ & 3.600 & 0.507 & 3.440 & 0.507 & 3.613 & 0.558 & 0.823 & 0.443 \\
\hline $\begin{array}{l}\text { I would describe the vid- } \\
\text { eo lessons as being highly } \\
\text { interesting. }\end{array}$ & 3.400 & 0.632 & $3 \cdot 320$ & 0.476 & 3.516 & 0.508 & 0.981 & 0.380 \\
\hline $\begin{array}{l}\text { I would recommend use } \\
\text { of the video lessons to my } \\
\text { colleagues. }\end{array}$ & 3.267 & 0.594 & $3 \cdot 320$ & 0.557 & 3.452 & 0.506 & 0.726 & 0.488 \\
\hline $\begin{array}{l}\text { The video lessons make } \\
\text { me spend more time } \\
\text { studying to acquire prac- } \\
\text { tical skills. }\end{array}$ & 3.333 & 0.617 & 3.280 & 0.614 & 3.419 & 0.502 & 0.427 & 0.654 \\
\hline $\begin{array}{l}\text { I am satisfied with my } \\
\text { learning from the video } \\
\text { lessons. }\end{array}$ & 3.600 & 0.632 & 3.48 & 0.510 & 3.645 & 0.486 & 0.695 & 0.503 \\
\hline
\end{tabular}

*Statistically significant at .05 level, $\mathrm{df}=2$ for numerator and 68 for denominator (computed $\mathrm{F}$ value $\left.>\mathrm{F}_{0.05(2,68)}=3.132\right) ; \mathrm{p}$-value $=0.012<0.05$ 


\section{Conclusion and Implications for Practice}

This study is one of the few attempts to investigate learners' acceptance of and satisfaction with video lessons used to teach practical skills at a distance. Lack of user acceptance and satisfaction could be an impediment to the successful adoption of any new technology or product, including the use of video-based instructional materials to teach practical lessons at a distance. Fortunately, the results of this study showed high acceptance and satisfaction of the distance learners with the use of the video-based instructional materials to teach them practical skills. The learners expressed high perceived usefulness, ease of use, and intention to use the video-based instructional materials in learning practical skills in blocklaying and concreting. The learners also found the materials relevant, effective, enjoyable, and interesting, and would recommend them to their fellow students for use. The expressed high acceptance of and satisfaction with the video-based instructional materials was, to a large extent, also uniform among the respondents of the three study centres covered by the study. Thus, irrespective of location, the learners generally appeared positive about their experiences in the use of the video lessons to learn practical skills at a distance.

The study has demonstrated that the use of video-based instructional materials to teach practical skills at a distance appears promising. The President's Special Initiative on Distance Learning (PSI-DL), which runs the programme, will undoubtedly feel encouraged by the findings and can better justify its activities when it devotes significant organizational resources to video-based instructional materials used to teach practical skills at a distance. Although the findings are encouraging, PSI-DL needs to reflect on them, identify the possible causes of the high learner acceptance and satisfaction, and thereafter, institute measures to maintain the identified success factors so that the expressed high learner acceptance and satisfaction do not slip.

The primary goal of using the video-based instructional materials is to support and enhance the learning of practical skills at a distance. This goal cannot be achieved if learners are not satisfied with the materials and do not accept to use them. The findings provide distance education practitioners (including tutors, instructional designers, academic institutions, and open schools) important considerations regarding the design and subsequent use of video lessons to teach practical skills at a distance. The usefulness and ease of use of the instructional materials should be of prime concern if the learners are to be satisfied with them. Practitioners must strive to produce materials for the learning of practical skills at a distance that learners find useful, easy to use, and enjoyable.

In this study, the measure of actual usage of the video-based instructional materials by learners was subjective and based on the opinion of the respondents through a self-completion questionnaire. It is recommended that future studies should combine the use of both objective and subjective approaches to measure actual usage. 


\section{References}

Anderson, L. W. (1985). Likert scales. In International Encyclopaedia of Education (Vol. 5, pp. 3082-3084). Oxford: Pergamon Press.

Borg, W. R., \& Gall, M. D. (1983). Educational research: An introduction. New York: Longman.

Canarie Learning Program. (2004). Evaluation report: Virtual veterinary medicine learning community. Retrieved from http://www.ovc.uoguelph.ca/Canarie/Phase2/ Web/Evaluation\%20Report.pdf

Casley, D., \& Kumar, K. (1988). The collection, analysis, and use of monitoring and evaluation data. New York: The John Hopkins University Press.

Davis, F. D. (1993). User acceptance of information technology: System characteristics, user perceptions, and behavioral impacts. International Journal of Man-Machine Studies, 38, 475-487. Retrieved from http://deepblue.lib.umich.edu/bitstream/2027.42/30954/1/0000626.pdf

Davis, F. D. (1995). Measuring user acceptance of emerging information technologies: An assessment of possible method of biases. Proceedings of the 28th Annual Hawaii International Conference on System Sciences (Vol. 4, pp. 729-736). Washington, D.C.: IEEE Computer Society Press.

Dillon, A. (2001). User acceptance of information technology. In W. Karwowski (Ed.), Encyclopaedia of human factors and ergonomics. London: Taylor and Francis.

Donkor, F. (2010). The comparative instructional effectiveness of print-based instructional materials for teaching practical skills at a distance. International Review of Research in Open and Distance Learning, 11(1), 96-115.

Downie, N. M. (1967). Fundamentals of measurements: Techniques and practices (2nd ed.). London: Oxford University Press.

Fusilier, M., \& Durlabhji, S. (2005). An exploration of student Internet use in India: The technology acceptance model and the theory of planned behaviour. Campus Wide Information Systems, 22(4), 233-246.

Ghee, T. T., \& Heng, L. T. (2008). Efficacy of multimedia teaching instruction in elementary Mandarin class. Proceedings of the Third Centre for Language Studies (CLS) International Conference (pp. 686-697). Retrieved from http://www.fas.nus.edu. sg/cls/clasic2008/Tan Lim.pdf

Hampton, C. (2002). Teaching practical skills. In A. K. Mishra \& J. Bartram (Eds.), Perspectives on distance education: Skills development through distance education 
(pp. 83-91). Vancouver, Canada: Commonwealth of Learning. Retrieved from http://www.col.org/SiteCollectionDocuments/Skills_Chaptero9.pdf

Johnson, R. B., \& Christensen, L. B. (2008). Educational research: Quantitative, qualitative, and mixed approaches (3rd ed.). Los Angeles: Sage.

Jung, I. (2005). Innovative and good practices of open and distance learning in Asia and the Pacific (A study commissioned by UNESCO, Bangkok). Retrieved from http:// unesdoc.unesco.org/images/o015/001529/152961e.pdf

Kearney, M., \& Treagust, D. F. (2001). Constructivism as a referent in the design and development of a computer program using interactive digital video to enhance learning in physics. Australian Journal of Educational Technology, 17(1), 64-79.

King, W. R., \& He, J. (2006). A meta-analysis of the technology acceptance model. Information and Management, 43(6), 740-755.

Kinnear, P. R., \& Gray, C. D. (1992). SPSS/PC+ made simple. Hove, U.K.: Lawrence Erlbaum Associates Ltd.

Legris, P., Ingham, J., \& Collerette, P. (2003). Why do people use information technology? A critical review of the technology acceptance model. Information and Management, 4O(3), 191-204.

Masrom, M. (2007, May). Technology acceptance model and e-learning. 12th International Conference on Education, Sultan Hassanal Bolkiah Institute of Education, Universiti Brunei Darussalam. Retrieved from http://eprints.utm.my/5482/1/ MaslinMasrom2006 Techn.pdf

Mishra, S. (2001). Designing online learning. Vancouver, Canada: Commonwealth of Learning. Retrieved from http://www.col.org/SiteCollectionDocuments/KS2001$\underline{02}$ online.pdf

Neuman, W. L. (2000). Social research methods: Qualitative and quantitative approaches (4th ed.). Boston: Allyn and Bacon.

Osuala, E. C. (1993). Introduction to research methodology. Onitsha, Nigeria: AfricanaFep Publishers Limited.

Piotrow, P., Khan, O., Lozare, B., \& Khan, S. (2000). Health communication programs: A distance education class within the John Hopkins University School of Public Health Distance Education Program. In M. Khosrowpour (Ed.), Web-based learning and teaching technologies: Opportunities and challenges. Hershey, PA: Idea Group Publishing.

Schepers, J., \& Wetzels, W. (2007). A meta-analysis of the technology acceptance model: 
Investigating subjective norm and moderation effects. Information and Management, 44(1), 90-103.

Tooth, T. (2000). The use of multimedia in distance education. Vancouver, Canada: Commonwealth of Learning. Retrieved from http://www.col.org/SiteCollectionDocuments/KS2000\%20multimedia.pdf

Turner, M., Kitchenham, B., Brereton, P., Charters, S., \& Budgen, D. (2010). Does the technology acceptance model predict actual use? A systematic literature review. Information and Software Technology, 52, 463-469.

Zhang, D., Zhou, L., Briggs, R. O., \& Nunamaker, J. F., Jr. (2006). Instructional video in e-learning: Assessing the impact of interactive video on learning effectiveness. Information and Management, 43, 15-27.

\section{Athabasca University $\mathbf{1}$}

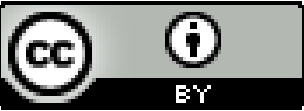

